Alcir Almeida de Souza

\title{
Evangelização Como Ação Contextual-Libertadora Um Estudo Teológico Pastoral da Teologia de Orlando Costas
}

Tese de Doutorado

Tese apresentada como requisito parcial para obtenção do grau de Doutor pelo Programa de Pósgraduação em Teologia do Departamento de Teologia da PUC-Rio.

Orientador: Prof. Dr. Abimar Oliveira de Moraes

Rio de Janeiro

Setembro de 2011 


\title{
Pontifícia Universidade $\mathrm{C}_{\text {atólica }}$

Alcir Almeida de Souza

\author{
Evangelização Como Ação Contextual-Libertadora \\ Um Estudo Teológico Pastoral da Teologia de Orlando Costas
}

\begin{abstract}
Tese apresentada como requisito parcial para obtenção do grau de Doutor pelo Programa de Pós-Graduação em Teologia do Departamento de Teologia do Centro de Teologia e Ciências Humanas da PUC-Rio. Aprovada pela Comissão Examinadora abaixo assinada.
\end{abstract}

Prof. Abimar Oliveira de Moraes Orientador Departamento de Teologia - PUC-Rio

Prof. Mário de França Miranda Departamento de Teologia - PUC-Rio

Prof $^{\mathrm{a}}$. Tereza Maria Pompéia Cavalcanti

Departamento de Teologia - PUC-Rio

Prof. Alessandro Rodrigues Rocha

FATERJ

Prof. Carlos Ribeiro Caldas Filho Universidade Presbiteriana Mackenzie

Prof $^{a}$. Denise Berruezo Portinari Coordenadora Setorial de Pós-Graduação e Pesquisa do Centro de Teologia e Ciências Humanas - PUC-Rio 
Todos os direitos reservados. É proibida a reprodução total ou parcial do trabalho sem autorização da Universidade, do autor e do orientador.

\section{Alcir Almeida de Souza}

Graduou-se em teologia no Seminário Teológico do Oeste do Rio de Janeiro, em 1997, e em Licenciatura em Letras (Português/Literatura) pela Universidade Federal de Viçosa, em 2006. Concluiu o mestrado em teologia/missiologia no Centro Evangélico de Missões, em 2002. É pastor da Convenção Batista Brasileira, com atuação na área de formação teológica. É professor, Coordenador Acadêmico e de Pós-graduação do Centro Evangélico de Missões, em Viçosa, MG, e professor visitante em Seminários e faculdades teológicas no Brasil e em Portugal.

Ficha Catalográfica

Souza, Alcir Almeida de

Evangelização como ação contextual-libertadora: um estudo teológico pastoral da teologia de Orlando Costas / Alcir Almeida de Souza ; orientador: Abimar Oliveira de Moraes. - 2011.

$267 \mathrm{f.} ; 30 \mathrm{~cm}$

Tese (doutorado) - Pontifícia Universidade Católica do Rio de Janeiro, Departamento de Teologia, 2012.

Inclui bibliografia

1. Teologia - Teses. 2. Costas, Orlando. 3. Missão. 4. Pastoral. 5. Evangelização. 6. Libertação. 7. Inculturação. I. Moraes, Abimar Oliveira de. II. Pontifícia Universidade Católica do Rio de Janeiro. Departamento de Teologia. III. Título.

CDD: 200 
A Ana Claudia, minha eterna companheira, com quem divido meus sonhos e multiplico meu amor. A Lucas e Ana Karis, heranças do Senhor, que a cada dia nos fazem conhecer mais o dom de amar. 


\section{Agradecimentos}

Ao Deus trinitário, fonte de toda vida, que nos acolhe em todo tempo e oferece a graça libertadora da salvação.

Aos meus irmãos Lúcia Maria, Ana Cristina, Evaldo, Ivanir e Ismair por me ajudarem a ser o que sou hoje, e me ensinarem o amor para além de mim mesmo.

Ao meu orientador Professor Dr. Abimar Oliveira de Moraes, pelo estímulo, dedicação e cumplicidade. Sua disposição em assumir a orientação foi fundamental para a realização deste trabalho.

Ao CNPq e à PUC-Rio, pelos auxílios concedidos, sem os quais este trabalho não poderia ter sido realizado.

Ao CTCH - Centro de Teologia e de Ciências Humanas e do Departamento de Teologia da PUC-Rio e todos os docentes, funcionários e colegas de curso que me ajudaram a concluir esta jornada.

Ao Centro Evangélico de Missões, aos queridos membros do conselho diretor, professores e funcionários pelo companheirismo e apoio em todo o tempo.

Aos parentes e amigos que nos acolheram em Teresópolis, pelo carinho e cuidado dispensados à nossa família.

A Overseas Council International pelo auxílio no início do curso. 


\section{Resumo}

Souza, Alcir Almeida; Moraes, Abimar Oliveira de. Evangelização Como Ação Contextual-Libertadora: Um Estudo Teológico Pastoral da Teologia de Orlando Costas. Rio de Janeiro, 2011. 267p. Tese de Doutorado - Departamento de Teologia, Pontifícia Universidade Católica do Rio de Janeiro.

A presente tese traz como título "Evangelização como Ação ContextualLibertadora - Um Estudo Teológico Pastoral da Teologia de Orlando Costas”. Ela tem como objetivo posicionar a proposição da Teologia da Evangelização Contextual do referido autor como um horizonte epistemológico adequado para se (re)pensar a teologia pastoral, e mais especificamente o caráter evangelizador da Igreja nos dias atuais. Isto se dá principalmente pelo fato de que Costas desenvolve um método teológico com abrangência contextual e histórica que tem seu cerne em uma teologia eminentemente dialógica. Como os novos dias se configuram não apenas como um novo locus para a vivência da fé cristã, mas também para a proclamação das boas novas do reino, esta pesquisa acentua a necessidade de se desenvolver uma (re)nova(da) leitura da missão da Igreja, à luz do reino de Deus. Inspirados na dinâmica trinitária os cristãos podem encontrar possibilidades criativas de responder à interpelação divina de amor-serviço, entendendo que a missão cristã é a continuidade, na força do Espírito, da missão libertadora que brota do coração de Deus, transbordante de amor pela sua criação. Neste sentido, esta tese contribui ainda para a recuperação de um serviço evangelizador que se realiza como transbordamento do amor divino na realidade humana, que convida os homens e mulheres a uma experiência de fé articulada não como dogma, adesão religiosa ou mera experiência de êxtase, mas como uma orientação peculiar da existência que interpela a liberdade humana a fazer uma opção pelo Deus trinitário como fonte de vida.

\section{Palavras-chave}

Orlando Costas; missão; pastoral; evangelização; libertação; inculturação. 


\section{Abstract}

Souza, Alcir Almeida; Moraes, Abimar Oliveira de (Advisor). Evangelism as Contextual-Liberating Action: A Theological Pastoral Study of the Theology of Orlando Costas. Rio de Janeiro, 2011. 267p. Doctoral Thesis - Departamento de Teologia, Pontifícia Universidade Católica do Rio de Janeiro.

The present dissertation has the title "Evangelism as Contextual-Liberating Action, a Theological Pastoral Study of the Theology of Orlando Costas”. It has the goal to locate a proposition of the Theology of Contextual Evangelism of the mentioned author with an appropriate epistemological horizon in order to reconsider a pastoral theology, and more specifically the evangelistic character of the Church in the present days. This is done mainly by the fact that Costas develops a theological method with contextual and historical broadness which has its key in a theology which is eminently dialogical. As the present days are configured not only as a new locus for living the Christian faith, but also as the proclamation of the good news of the kingdom, this research emphasizes the need to develop a (re)new(ed) reading about the mission of the Church, in the light of the kingdom of God. Inspired by the trinitarian dynamic, Christians can find creative possibilities to respond to the divine summons to love-in-service, understanding that Christian Mission is a continuity, in the strength of the Spirit, of the liberating mission which flows from the heart of God, his overflowing love for his creation. In this sense, this dissertation offers a contribution to recover an evangelistic service which realizes itself as overflowing God's love in the human context, inviting men and women to an experience of faith which is articulated not as a dogma, religious adhesion or a simple experience of ecstasy, but as a specific orientation of their existence, which challenges human freedom to make an option for the Trinitarian God as the source of life.

\section{Keywords}

Orlando Costas; mission; pastoral; evangelism; liberation; enculturation. 


\section{Sumário}

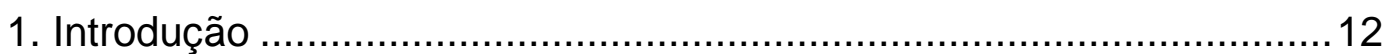

2. Teologia de Orlando Costas em Perspectiva .................................22

2.1. Itinerário Ministerial ...............................................................23

2.1.1.Conversão a Cristo: do autocentramento àa salvação ....................24

2.1.2. Conversão à Cultura: do fundamentalismo anglo-saxão

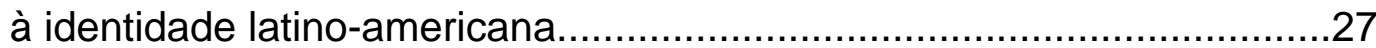

2.1.3. Conversão sociopolítica: abertura ao mundo dos explorados ........29

2.1.4. O chamado macedônico: a opção pelos pobres ..........................34

2.2. Elementos teológicos prévios na construção de uma

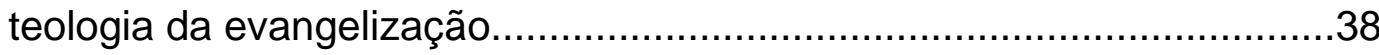

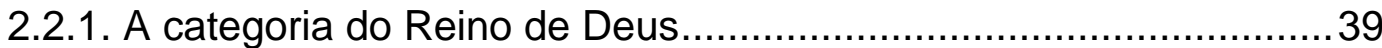

2.2.1.1. A dimensão cristológica do Reino de Deus...............................39

2.2.1.2. A dimensão eclesiológica do Reino de Deus ...........................42

2.2.1.3. A dimensão escatológica do Reino de Deus ............................ 45

2.2.2. O Conceito de Missão da Igreja ...........................................49

2.2.3. O Conceito de Conversão ...............................................60 60

2.2.3.1. Conversão na perspectiva do seguimento de Jesus ..................61 61

2.2.3.2. Perspectiva contextual de Conversão ..................................... 64

2.2.4. O Conceito de Salvação ......................................................69

2.2.4.1. Pecado e Salvação em perspectiva bíblica ...............................69

2.2.4.2. Sinais de salvação nas Escrituras ....................................... 72

2.2.4.3. Pecado e Salvação na América Latina.................................... 74

3. Horizontes de Complexidade da ação querigmática da Igreja ............77

3.1.Horizonte de Complexidade Cultural .......................................... 79

3.1.1. Cultura moderna e secularização ......................................... 80 
3.1.2. A autonomia da sociedade e do indivíduo................................ 82

3.1.3. A dessacralização do mundo .................................................... 84

3.1.4. A Recuperação do sentido de Deus neste novo contexto .............. 86

3.2. Horizonte de Complexidade Antropológica ....................................88

3.2.1. A dignidade da pessoa humana .........................................90

3.2.2. A pessoa humana e a dinâmica da existência .............................94

3.2.3. A humanização no amor....................................................... 96

3.3. Horizonte de Complexidade Sociopolítica .....................................98

3.3.1. Recuperando a linguagem da libertação....................................99

3.3.2. Recuperando a integralidade da mensagem de libertação .......... 103

3.3.3. A mensagem de libertação como chave no Kerigma do

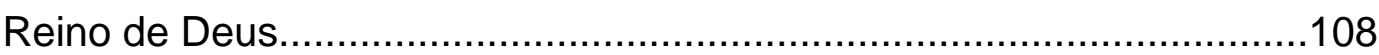

3.4. Evangelização e Contexto no horizonte teologal de

Orlando Costas ...................................................................... 111

3.4.1. O contexto como ambiente teologal ....................................... 111

3.4.2. A evangelização contextual: base da ação evangelizadora .........113

4. Desafios ad intra para a pastoral evangelizadora da Igreja diante dos desafios atuais.........................................................122

4.1. A Evangelização e o Crescimento da Igreja.................................123

4.1.1. A ação da igreja e os propósitos de Deus para seu povo. ...........127

4.1.2. As marcas de Cristo e o crescimento integral da Igreja ...............128

4.1.3. A presença e a operação do Espírito no crescimento da Igreja ...130

4.1.4. A expansão quantitativa: a comunidade que vive para os outros. 133

4.1.5. O crescimento orgânico e a funcionalidade da comunidade ........ 134

4.1.6. O crescimento conceitual e a inteligência da fé ........................ 135

4.1.7. O crescimento encarnacional e o serviço ao mundo ...................137

4.2. Evangelização e discipulado missionário ..................................... 139

4.2.1.O seguimento de Jesus como reorientação de vida e compromisso ........................................................................... 145

4.2.2. O seguimento de Jesus como participação em sua missão......... 146

4.2.3. O seguimento como obediência a Jesus................................. 149

4.3. A Evangelização diante dos desafios dos novos movimentos religiosos. 
4.3.1. A Fé cristã na pós-modernidade: O espírito consumidor

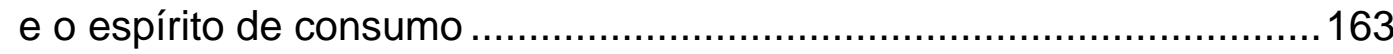

4.3.1.1. O Deus da teologia da prosperidade ................................... 164

4.3.1.2. A consciência da ação divina ........................................... 165

4.3.1.3. A vida no Espírito no ambiente neopentecostal ......................167

4.3.2. O esvaziamento cristológico da religiosidade contemporânea.....169

5. Desafios ad extra para a ação evangelizadora da Igreja ..................176

5.1. Evangelização e Ecumenismo ................................................. 177

5.1.1. Um Pacto Ecumênico - Do Deus trinitário ao amor-serviço......... 179

5.1.2. A Evangelização integral é evangélica e ecumênica................... 183

5.1.3. A evangelização baseada em uma "hermenêutica ecumênica" ... 185

5.1.4. A Promoção da justiça, fruto da evangelização

integral, como espaço comum da vivência ecumênica ......................... 188

5.1.5. A vivência ecumênica como paradigma de uma

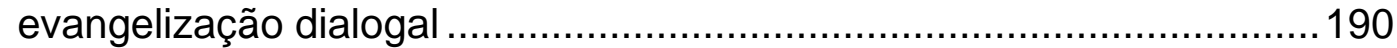

5.2. Evangelização e Inculturação da fé......................................... 192

5.2.1.Revelação e fé no horizonte cultural ......................................... 195

5.2.2. Inculturação da fé como ação teologal ....................................197

5.2.3. Inculturação da fé na dinâmica trinitária ................................. 200

5.2.4. Evangelho e cultura - parceiras na construção de um

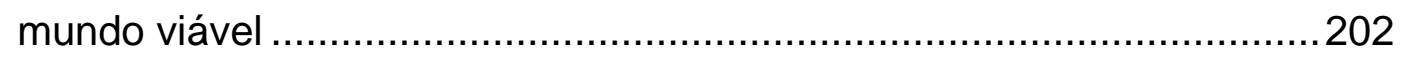

5.2.5. Inculturação da fé em um mundo globalizado -

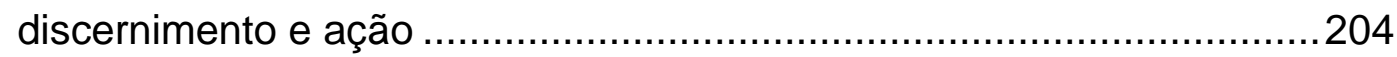

5.2.6. Inculturação da fé no mundo dos pobres .................................207

5.3. Evangelização e a Práxis Libertadora Integral ............................. 209

5.3.1. Um evangelho que vem do outro lado da porta -

um novo lugar de salvação.................................................... 212

5.3.2. Evangelização contextual como nova visão da evangelização ....215

5.3.3.A libertação integral como ação salvífica em

um universo desintegrado

5.3.4. A cultura de massa - um desafio a práxis libertadora integral .....219

5.3.5. A paz como face libertadora da mensagem evangélica ..............2221 


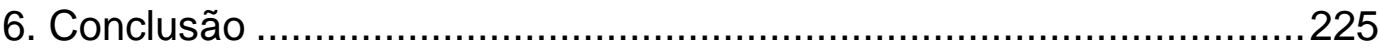

7. Referências Bibliográficas ..........................................................233

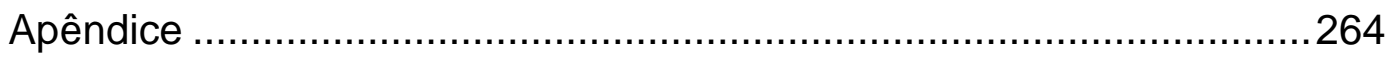

